\title{
Marxismo, a alienação e o tempo histórico da barbárie social do capital
}

\author{
Giovanni Alves \\ Universidade Estadual Paulista Júlio de Mesquita Filho (Unesp, Marília)
}

\section{Marxismo, a alienação e o tempo histórico da barbárie social do capital}

Resumo: O objetivo do ensaio é expor a alienação/estranhamento como o problema crucial do nosso tempo histórico, buscando salientar os significados do conceito de "autotranscendência positiva da alienação", considerada por István Meszáros, como sendo o eixo da reflexão marxiana nos Manuscritos econômico-filosóficos. Para tanto, discorre sobre o novo registro histórico da Aufhebung nas condições da crise estrutural do capital e a vigência do capitalismo global como capitalismo manipulatório. Aborda a centralidade ontológica da problemática da vida cotidiana e o estranhamento na perspectiva da crítica radical do trabalho. Finalmente, coloca elementos para refletir, na perspectiva do marxismo radical, sobre a transição como sendo o problema de produção dos sujeitos humanos, capazes da autotranscendência positiva da alienação.

Palavras-chave: Alienação. Trabalho. Marxismo. Cotidiano.

\section{Marxism, Alienation and the Historic Time of the Social Barbarity of Capital}

Abstract: The purpose of this essay is to explore alienation as a crucial problem of our historic time, seeking to emphasize the meanings of the concept of "positive self-transcendence of alienation", which is considered by István Meszáros as the central axis of Marxian reflection in the Economic-Philosophic Manuscripts. To do so, it looks at the new historic registration of Aufhebung considering the conditions of the structural crisis of capital and the rule of global capitalism as manipulative capitalism. It addresses the ontological centrality of the problematic of everyday life and alienation from the perspective of the radical criticism of work. Finally, it raises elements for reflection, from a radical Marxist perspective, about the transition as being the problem of production of human subjects, capable of positive self-transcendence from alienation.

Keywords: Alienation. Labor. Marxism. Everyday life. 


\section{Introdução}

Em um país capitalista como o Brasil, onde o marxismo sofreu a derrota da dialética (KONDER, 2010), as investigações marxistas tendem a padecer do tertium datur (terceira via possível) necessário para a apreensão concreta das novas formas de alienação do capital na era da barbárie social. As investigações marxistas no Brasil sobre o tema da alienação não são apenas escassas, mas carentes de imaginação dialética, o que impede a problematização dos pressupostos marxianos originários, tendo em vista as novas condições históricas de vigência radical do fetichismo da mercadoria e a plenitude do trabalho abstrato.

$\mathrm{Na}$ verdade, a apreensão concreta das novas formas de alienação/estranhamento na era da mundialização do capital implica o desenvolvimento da teoria do fetichismo, capaz de explicar a persistência da ordem burguesa nas condições da crise estrutural do capital. Do viés que reduz de tal maneira a categoria do proletariado que impossibilita pensá-lo como sujeito histórico efetivo do socialismo (LESSA, 2008), às análises críticas que despercebem as novas particularidades da exploração capitalista sob o toyotismo como "momento predominante" da reestruturação do capital - para esses autores, o horizonte último é a crítica do fordismo-taylorismo (BRAGA, 2009) -, temos sintomas de uma "dialética" incapaz de apreender a riqueza concreta do novo.

Nossa hipótese é que o tema da alienação (ou estranhamento) tornou-se a proposição crucial da investigação marxista hoje. Não se trata apenas de mais uma das questões de discussão deste universo, mas é $o$ tema candente a partir do qual deve-se elaborar a crítica do capital como modo de controle estranhado do metabolismo social e a reflexão necessária sobre as possibilidades históricas da emancipação humana nas condições da barbárie social.

Por isso, podemos dizer que o livro A teoria da alienação em Marx, de István Mészáros, publicado em 1970, tornou-se um marco no marxismo do século 20. No alvorecer da era da mundialização do capital, o livro do filósofo húngaro coloca a agenda de investigação crítica necessária para pensarmos a práxis capaz de superar não apenas o capitalismo, mas a ordem capital (MÉSZÁROS, 2006).

O que Mészáros nos apresenta nesse denso estudo, republicado em língua portuguesa em 2006, é mais um ponto de partida de uma reflexão fundamental e necessária do que propriamente um ponto de chegada para pensarmos o complexo de alienações sob a mundialização do capital.

Neste pequeno ensaio, iremos apenas pontuar algumas questões a partir da tese central de Mészáros. Por exemplo, na introdução de sua obra clássica, o filósofo marxista húngaro salienta que o problema da "autotranscendência positiva da alienação" é o eixo da reflexão marxiana nos Manuscritos econômico-filosóficos. Mészáros é inclusive categórico em afirmar que o sistema de Marx nasceu tão logo o problema da transcendência ou o problema da "unidade da teoria e da prática" - foi concretizado como a "negação e supressão" da "autoa-

a apreensão concreta das novas formas de alienação/ estranhamento na era da mundialização do capital implica o desenvolvimento da teoria do fetichismo, capaz de explicar a persistência da ordem burguesa nas condições da crise estrutural do capital. lienação do trabalho" (MARX, 2004).

Não apenas a introdução do conceito de "trabalho alienado", como observa o filósofo húngaro, mas o próprio discernimento histórico do movimento da classe social do proletariado seria o "ponto de Arquimedes" capaz de traduzir o programa da "negação e supressão" da "autoalienação do trabalho", em realidade efetiva. O que significa que a teoria da classe (e consciência de classe) do proletariado em Marx pressupõe efetivamente, como lastro fundamental (e fundante), a teoria da alienação do trabalho.

No livro A condição de proletariedade (ALVES, 2010), salientamos a importância de apreendermos a teoria da classe social do proletariado, não a partir da teoria da exploração com a disjunção estrutural trabalho produtivo-trabalho improdutivo demarcando o lugar da classe do proletariado, mas sim a partir da teoria do estranhamento e de seus atributos existenciais que demarcam o que denominamos "condição de proletariedade". Na verdade, não é a condição de proletariedade que constitui o lugar da classe social do proletariado, mas sim o movimento de "negação e supressão da autoalienação do trabalho", em sua dimensão contingente ou dimensão necessária. O que significa que a transcendência da autoalienação do trabalho, que Marx colocou como sendo o problema da "unidade da teoria e da prática", é o problema da consciência de classe capaz de constituir efetivamente o lugar ontológico da classe social do proletariado. Na perspectiva histórico-ontológica, só há classe social se houver consciência de classe. 
É importante compreendermos o pleno significado histórico-ontológico do problema da "autotranscendência positiva da alienação", posto por István Mészáros como sendo o eixo da reflexão marxiana nos Manuscritos econômico-filosóficos:

a) O texto dos Manuscritos econômico-filosóficos, ou Manuscritos de Paris, é de 1844, conjuntura histórica pré-revolucionária marcada pela primeira grande crise do capitalismo industrial e a ascensão das massas proletárias. Nos escritos de juventude, assim como no artigo Glosas críticas marginais ao artigo ' $O$ rei da Prússia e a reforma social', também de 1844, Marx já salientava o movimento do proletariado e a própria categoria de proletariado como o sujeito-que-nega-o-estado-de-coisas-existente na medida em que se põe em movimento. Então, está claro que o eixo categorial organizador naquele momento da reflexão marxiana é a Aufhebung como movimento histórico posto a partir da alienação como pressuposto do sujeito in fieri.

b) A ideia meszariana da centralidade da autotranscendência positiva da alienação na reflexão de Marx, leva a pensar que a classe social implica efetivamente consciência de classe no sentido de consciência como pressuposto da Aufhebung. Desse modo, teríamos a seguinte equação ontológica, onde o sinal de igualdade significa implicação necessariamente pressuposta: Aufhebung $=$ consciência $($ de classe) $=$ classe (sujeito coletivo que nega - aliás, nega e supera, no sentido da autotranscendência positiva).

c) Na leitura meszariana de Marx, a ideia de Aufhebung significa movimento social do sujeito coletivo capaz de negar o estado de coisas existente (o capital), um movimento sociometabólico alternativo, mais propriamente social que político, e, portanto, que nasce por baixo, abrangendo a totalidade da vida social. É por isso um movimento global da classe, capaz de ir além das parcialidades do movimento político ou sindical.É um movimento social capaz de Aufhebung. Podemos dizer que o sujeito coletivo, capaz de negar o estado de coisas existente (o capital), imerso na condição de proletariedade, constitui-se como classe do proletariado, na medida em que seu movimento social - mais social que político, propriamente dito - tem como implicação, necessariamente pressuposta, um modo de consciência social historicamente determinado: a consciência de classe.

d) Nesse caso, a radicalidade do movimento social significa que ele atinge os fundamentos, isto é, o próprio homem, ou as relações sociais que têm na vida cotidiana seu ponto nevrálgico. Sindicatos e partidos, na ótica meszariana, são incapazes de promover a Aufhebung, tendo em vista o seu parcialismo. Na medida em que o capital é um processo estranhado global, ele exige, para sua superação, processos globais, isto é, capazes de abranger a totalidade da vida social - eis a condição sine qua non para a Aufhebung. A consciência de classe, como implicação necessariamente pressuposta do proletariado, constituída pelas individualidades pessoais de classe imersas na condição de proletariedade, implica não apenas o momento econômico-corporativo ou o momento ético-político que caracterizam o em-si e o para-si da classe in fieri; mas sim, o momento sociometabólico capaz de promover a Aufhebung necessária, isto é, a autotranscendência positiva da alienação. O ponto nevrálgico do momento sociometabólico é a vida cotidiana.

\section{A autotranscendência positiva da alienação}

A ideia de autotranscendência positiva tem seu significado exposto no prefixo "auto" e no qualificativo "positiva". Vejamos suas implicações significativas:

a) É "autotranscendência" no sentido de que é uma transcendência efetivada pelo próprio sujeito alienado, isto é, a superação deve ser obra dos próprios "trabalhadores assalariados" e não de governos, partidos ou sindicatos - nenhuma destas instâncias político-sindicais é capaz de promover, por si só, a emancipação do homem-que-trabalha. Ao dizer "trabalhadores assalariados", dizemos proletários no sentido radical da palavra, isto é, "a massa da humanidade como massa totalmente "destituída de propriedade" (MARX; ENGELS, 1987). Por isso, os sujeitos alienados têm de ter capacidade para superarem, por si próprios, o estado de alienação. Nesse caso, salienta-se como necessidade radical para que haja efetivamente a "autotranscendência", a formação (e constituição) de sujeitos humanos capazes de autonomia radical (auto-organização de cultura).

b) É autotranscendência "positiva" no sentido de propor para si uma alternativa positiva - concreta - à alienação, construindo assim um sociometabolismo alheio ao sistema social da alienação, baseado na propriedade privada dos meios de produção e na hierarquia social do trabalho. Portanto, coloca-se a necessidade da radicalidade positiva, não meramente insurgente, à ordem burguesa. Ela é positiva no sentido de propor uma nova ordem sociometabólica capaz de ser alternativa - no plano prático-sensível - à ordem alienada. Eis o sentido do "momento sociometabólico" salientado acima, movimento propositivo da classe capaz de alterar, para além de si, as relações sociais que constituem a sua vida cotidiana. A positividade radical tem o caráter propositivo para além da ordem do capital, implicando, inclusive, em tirar as consequências radicais de elementos contraditoriamente compositivos da própria ordem burguesa (partindo de Marx, diríamos: discernir - eis a palavra - embriões da nova ordem no interior da velha ordem). 
Assim, coloca-se a classe social do proletariado como sujeito emancipador, não apenas no sentido de "coveiro da velha ordem burguesa", mas "parteiro da nova sociedade de produtores auto-organizados". Desse modo, na ótica de Mészáros, depois de Marx, o comunismo aparece como o movimento de homens e mulheres proletários capazes de construir coletividades auto-organizadas radicalmente democráticas (o que pressupõe negar - ou superar, no sentido positivo - o complexo de alienação).

\section{O novo registro histórico da Aufhebung}

Vamos problematizar algumas questões cruciais colocadas anteriormente, tendo em vista a nova temporalidade histórica do capital, caracterizada como barbárie social. Na verdade, a conjuntura histórica que emerge da processualidade contraditória da ordem hipertardia do capital, caracterizada pela vigência plena do trabalho abstrato e pelo fetichismo da mercadoria, com suas implicações no plano da consciência social, tendem a alterar significativamente o registro da luta de classes; isto é, alterou-se efetivamente no decorrer do século 20, principalmente no pós-guerra e na etapa de crise estrutural do capital, a natureza da espontaneidade proletária e seu metabolismo social.

O que significa que não estamos em 1844-1848, muito menos em 1905 ou 1917-1919, isto é, em conjunturas revolucionárias que explicitavam formas de ser candentes da classe do proletariado como sujeito vivo. A própria conjuntura de 1970-1973, marcada pelo movimento de ascensão de lutas operárias e estudantis no alvorecer da era da mundialização do capital, tem a sua particularidade concreta que se distingue da conjuntura posterior, caracterizada pela ofensiva neoliberal e pela reestruturação produtiva com a expansão do desemprego em massa nos países capitalistas centrais.

Durante os "trinta anos perversos" de capitalismo global, alterou-se radicalmente a espontaneidade da classe em movimento. Nesta nova temporalidade histórica do capital, ocorreu não apenas uma reestruturação política (neoliberalismo) ou reestruturação produtiva (toyotismo) sob o signo das revoluções tecnológicas de cariz informacional, ou mesmo uma reestruturação ideológica (pós-modernismo), mas ocorreu principalmente uma revolução cultural de cariz neoconservador no bojo da ampliação e intensificação do fetichismo da mercadoria e vigência plena do trabalho abstrato (ALVES, 2011).

A transformação das pessoas em mercadoria e a implicação da vida para o consumo no seio da "sociedade do espetáculo" alterou a qualidade-densidade do movimento histórico da "classe", promovendo a universalização da "condição de proletariedade" capaz de abrir novas possibilidades objetivas para a formação da consciência de classe e, por conseguinte, da própria classe social do proletariado. Entretanto, alterou-se o registro histórico da Aufhebung na medida em que a voracidade da manipulação assumiu dimensões qualitativamente novas no plano da subjetividade das massas, obstaculizando ou retardando a formação e constituição do sujeito humano capaz de dar resposta radical à condição de proletariedade.

$\mathrm{Na}$ crise estrutural do capital, em uma conjuntura de reação neoconservadora sob o capitalismio manipulatório, como diria Lukács, explicita-se uma profunda contradição entre a verdade candente: da (a) necessidade histórica da Aufhebung (no sentido de que as respostas parciais contra o capital são não apenas limitadas, mas insuficientes) e (b) os limites irremediáveis postos no movimento da própria classe ainda como "classe", cuja espontaneidade imersa na pré-consciência, portanto aquém da contingência e necessidade da consciência de classe em virtude do grau de manipulação, permanece muito distante da ação radical necessária para a autotranscendência positiva da alienação.

Portanto, nas condições históricas da barbárie social do capital, explicita-se com maior candência e densidade histórica qualitativamente nova o complexo de estranhamento. Em sua Ontologia do ser social, Georg Lukács (1970, p. 630) caracterizou o fenômeno do estranhamento do seguinte modo:

O desenvolvimento das forças produtivas é necessariamente também o desenvolvimento da capacidade humana, mas - e aqui emerge praticamente o problema do estranhamento - o desenvolvimento da capacidade humana não produz obrigatoriamente o desenvolvimento da personalidade humana. Ao contrário: justamente potencializando capacidades singulares, pode desfigurar, aviltar etc., a personalidade do homem.

Entretanto, sob a crise estrutural do capital, temos não apenas a contradição entre capacidades humanas e obstáculos sociais para a efetivação destas capacidades (o que Lukács caracterizou efetivamente como sendo o problema do estranhamento), mas a contradição entre necessidade histórica de Aufhebung como autotranscendência positiva da alienação e as condições objetivas (e subjetivas) adversas no tocante à posição do sujeito histórico para a realização das mesmas. 
$\mathrm{Na}$ época de crise estrutural do capital, coloca-se com radicalidade a insustentabilidade histórica do capital como modo de controle estranhado do metabolismo social e, ao mesmo tempo, a possibilidade efetiva de permanência da ordem burguesa global. Na medida em que não se põem elementos necessários para a própria Aufhebung, instaura-se a barbárie social como uma das possibilidades - já postas - de permanência crítica da ordem burguesa.

Parafraseando Antonio Gramsci, podemos dizer que se abre, com a crise estrutural do capital e a obstaculização e/ou retardamento da necessária Aufhebung ou autotranscendência positiva da alienação, uma época de morbidez social quando o que existia deixou de existir; e o que vem ainda não chegou.

\section{A vida cotidiana e o capitalismo manipulatório}

Duas ênfases teórico-metodológicas são cruciais para a reflexão crítica do último Lukács: primeiro, as questões da vida cotidiana; depois, o problema do estranhamento e a dimensão manipulatória do capitalismo tardio, cunhado por ele como "capitalismo manipulatório" (ALVES, 2010). Ora, o capitalismo global é efetivamente o capitalismo manipulatório na sua dimensão planetária.

Na verdade, a temática da vida cotidiana nas condições do capitalismo manipulatório remete efetivamente à emergência de uma nova dinâmica sociometabólica do capitalismo histórico onde a vida cotidiana - espaço-tempo da espontaneidade de classe em seu movimento pré-contingente, contingente e necessário torna-se ponto de partida para apreendermos os sinais (ou campos de possibilidades concretas) da autotranscendência positiva dos sujeitos proletários alienados.

É na vida cotidiana que se põe a formação do sujeito-de-classe, capaz de negar e superar o capital como metabolismo social alienado. A revolução social como processo de Aufhebung ou autotranscendência positiva da alienação implica a formação da classe, isto é, processos de subjetivação ou formação de sujeitos humanos capazes de autonomia radical. Eis o campo da moralidade (Sichlichkeit, em Hegel) propriamente dita, onde se constrói, de baixo para cima, a nova ordem emancipada do capital.

Na ótica radical do último Lukács, a emancipação social do trabalho nasce da tessitura da vida cotidiana para além da ordem burguesa. Por exemplo, a ideia de democratização radical sustentada por ele implica processos cotidianos de elaboração positiva de dinâmicas alternativas à ordem alienada do capital. Assim, o exercício da autonomia radical ocorre no devir humano dos homens, na vida cotidiana como momento de processos mais amplos de transformação histórica.

\section{Considerações finais}

A ideia de revolução social e a autotranscendência positiva da alienação assumem, deste modo, um sentido processual de largo espectro histórico, de baixo para cima e de cima para baixo, onde a constituição de espaços de legalidade radicalmente democráticos aplaina o caminho para a efetiva autotranscendência positiva da alienação.

Numa perspectiva radical, revolução social significa a extinção do Estado político do capital. Entretanto, tal ideia não ocorre em uma grande noite, e sim implica um processo de democratização radical de largo espectro histórico. Trata-se do problema da transição, salientado por István Mészáros em sua obra Para além do capital. Na verdade, a superação deve levar anos e anos, décadas e décadas, nos quais sujeitos humanos autônomos tornam-se capazes de constituir espaços autogeridos na produção e reprodução social para além do Estado político do capital.

O socialismo do século 21 , na perspectiva radical, investe na formação e constituição da classe do proletariado como sujeito histórico capaz de autotranscendência da alienação, o que significa a formação de homens livremente socializados, capazes de exercer autonomamente o controle consciente e planejado do processo social da vida, implicando, desse modo, na democratização radical da vida cotidiana. Como observou Karl Marx, "para tanto, porém, se requer uma base material da sociedade ou uma série de condições materiais de existência, que, por sua vez, são o produto natural de uma evolução histórica longa e penosa" (MARX, 1986, p. 205).

Portanto, podemos dizer, na perspectiva do marxismo radical, que o problema da transição é o problema de produção da série de "condições materiais de existência", capazes de permitir o comunismo como a sociedade de homens livremente socializados; materialidade que implica necessariamente a produção dos sujeitos humanos, capazes da autotranscendência positiva da alienação. É ilusão acreditar que isso possa ocorrer - se ocorrer - sem uma "evolução histórica longa e penosa". A obstaculização e/ou retardamento desta longa e penosa - mas necessária - evolução histórica denomina-se barbárie social. É o tempo histórico em que vivemos. 


\section{Referências}

ALVES, G. A. P. A condição de proletariedade: a precariedade do trabalho no capitalismo global. Bauru: Praxis, 2009.

. Trabalho e subjetividade: o espírito do toyotismo na era do capitalismo manipulatório. São Paulo: Boitempo, 2011.

BRAGA, R. A vingança de Braverman: o infotaylorismo como contratempo. In: ANTUNES, R.; BRAGA, R. (Org.). Infoproletários: degradação real do trabalho virtual. São Paulo: Boitempo, 2009, p. 59-88.

KONDER, L. A derrota da dialética: a recepção das ideias de Marx no Brasil, até o começo dos anos trinta. São Paulo: Expressão Popular, 2010.

LESSA, S. Trabalho e proletariado. São Paulo: Cortez, 2008.

LUKÁCS, G. Per l'ontologia dell'éssere sociale II. Traduzione Alberto Scarponi. Roma: Editori Riuniti, 1981.

MÉSZÁROS, I. A teoria da alienação em Marx. Tradução de Isa Tavares. São Paulo: Boitempo, 2006.

MARX, K. O capital: crítica da economia política. Tradução de Regis Barbosa e Flávio R. Kothe. São Paulo: Abril Cultural, 1986. . Manuscritos econômico-filosóficos. Tradução de Jesus Ranieri. São Paulo: Boitempo, 2004.

MARK, K.; ENGELS, F. A ideologia alemã. Tradução de José Carlos Bruni e Marco Aurélio Nogueira. São Paulo: Hucitec, 1987.

\section{Giovanni Alves}

giovanni.alves@uol.com.br

Doutorado em Ciências Sociais pela Universidade Estadual de Campinas (Unicamp)

Professor livre-docente de Sociologia no Departamento de Sociologia e Antropologia Universidade Estadual Paulista Júlio de Mesquita Filho (Unesp)

\section{Unesp, Campus Marília}

Departamento de Sociologia e Antropologia

Av. Hygino Muzzi Filho, 737

Marília - São Paulo - Brasil

CEP: $17525-900$ 